UDK $630 * 38: 624.2 / .8$

$624.2 / .8: 556.16$

\title{
IZBOR TIPA RASPONSKE KONSTRUKCIJE I NJEN UTICAJ NA REGULACIJU BUJIČNOG TOKA
}

\section{Choice of the Bridge Construction Type and its Influence to the Regulation of Flood Flows}

\author{
Boro Kovačevićl ${ }^{1}$ Muhamed Bajrić ${ }^{2}$ Dževada Sokolović ${ }^{2}$
}

\begin{abstract}
There is a growing need for construction of new forest roads and modernization of the existing road network in Bosnia and Herzegovina forestry. Bridges on forest roads are, by the construction costs and technical characteristics, the most important structures on forest roads. The field research confirms a great number of old timber and steel bridges still in use on forest roads in Bosnia and Herzegovina. Majority of those bridges, however, are in bad condition, sometimes even closed for traffic or removed. The paper compares a short span timber, steel and reinforced concrete bridges, most frequently constructed on forest roads in Bosnia and Herzegovina, including composite bridges of simple structural systems, suitable for construction of short span bridges on forest roads. The presented results show considerable advantages compared to composite structures of timber, steel and reinforced concrete bridges. Unless specified, bridges constructions represent an optimal solution under circumstances of vast water flow such as in the cases of flood flow.
\end{abstract}

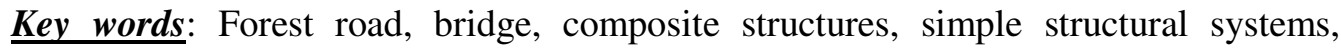
reconstruction, flood flow.

\section{Izvod}

Postoji rastuća potreba za izgradnju novih šumskih puteva i moderniziranje postojeće mreže puteva u šumskim gazdinstvima (šumarstvu) Bosne i Hercegovine. Mostovi na šumskim putevima su, prema troškovima izgradnje i tehničkim karakteritikama, najznačajnije strukture na šumskim putevima. Istraživanja na terenu potvrđuju da je veliki broj mostova napravljenih od drvne građe i čelika još uvijek u upotrebi na šumskim putevima Bosne i Hercegovine. Većina tih mostova su ipak u lošem stanju, katkad čak zatvorena za saobraćaj ili posve uklonjeni. Ovaj rad uspoređuje konstrukcije od drvne građe za kratko premošćenje, čelične i mostove od armiranog

\footnotetext{
${ }^{1}$ Komatsu d.o.o Sarajevo

${ }^{2}$ Šumarski Fakultet Univerziteta u Sarajevu - Faculty of Forestry University of Sarajevo
} 
betona, koji se najčešće grade na šumskim putevima u Bosni i Hercegovini, uključujući kompozitne mostove ili jednostavne strukturalne sisteme, koji su prikladni za izgradnju mostova za kratko premošćenje na šumskim putevima. Prikazani rezultati pokazuju značajne prednosti u usporedbi s kompozitnim strukturama od drvne građe, čelika i betonskih mostova. Osim navedenog, mostovske konstrukcije predstavljaju optimalno rješenje prilikom proticaja velikih voda, kakav je slučaj kod bujičnih tokova.

Ključne riječi: Šumski put, most, kompozitne strukture, jednostavni strukturni sistemi, rekonstrukcija, bujica.

\section{Uvod - Introduction}

Najznačajniji objekti na šumskim putevima, kako po troškovima gradnje tako i po svojim tehničkim karakteristikama jesu mostovi. Smanjenje troškova gradnje mostova na šumskim putevima uz istovremeno podizanje njihove kvalitete ima značajne implikacije na smanjenje troškova gradnje i podizanje kvalitete cjelokupne putne mreže u šumarstvu.

Nisu rijetki slučajevi da se umjesto mosta izvode propusti različitih profila iako situacija na terenu zahtijeva gradnju mosta. Ovakva rješenja se u praksi vrlo brzo pokažu neefikasna jer se oni vrlo brzo, usljed bujičnog nanosa zatvore, i nerijetko trajno onesposobe za propuštanje vode.

Pored gradnje novih objekata, značajno pitanje predstavlja i rekonstrukcija postojećih mostova na šumskim putevima. Poseban značaj ima pitanje rekonstrukcije drvenih mostova, a ovakvih objekata na šumskim putevima ima značajn broj. To potvrđuju i istraživanja provedena na šumskim područjima Travnika, Busovače, Fojnice te na području Treskavice i gornjeg toka rijeke Misoče. Na šumskim putevima ovih područja konstatiran je značajan broj drvenih mostova. Pregledani drveni mostovi, na kojima do vremena pregleda nisu vršeni rekonstruktivni zahvati, u pravilu su bili u lošem stanju, neki od njih čak i potpuno neupotrebljivi za saobraćaj. Naekima su, u bližoj ili daljoj prošlosti, izvršene rekonstrukcije. One su se u svim slučajevima odnosile na potpuno uklanjanje postojeće drvene rasponske konstrukcije i njenu zamjenu. Kao zamjenski konstruktivni elementi korišteni su uglavnom punostjeni vruće valjani čelični nosači I profila sa drvenim kolovozom, ili je ponovo rađena drvena konstrukcija sa gredama od pilanog prirodnog drveta. Na obalnim stubovima nisu vršeni nikakvi rekonstruktivni zahvati i uglavnom su zadržani u postojećem stanju. Izostavljanje obalnih stubava kao i "krila" mosta prilikom rekonstrukcije u najvećem broju slučajeva je također uzrok kratkotrajnosti izvršene rekonstrukcije. Navedeni nedostaci često dovode do urušavanja mostovske konstrukcije usljed podlokavanja postojećih obalnih stubova nadolaskom bujičnih voda.

Ovakve rekonstrukcije mogu se smatrati privremenim rješenjima. To se posebno odnosi na one mostove na kojim je rasponska konstrukcija rađena ponovo upotrebom drvenih nosača.

Rekonstrukcija se uglavnom radila od sirove četinarske pilanske građe i bez impregnacije. Česte promjene vlažnosti drveta usljed kišnih oborina ili nadolaska 
velikih voda, ubrzavaju propadanje ovakvih konstrukcija, te se njihova trajnost može procijeniti najviše na 5 do 10 godina. Upotreba čeličnih nosača sa drvenim kolovozom predstavlja nešto trajnije rješenje. No, i kod ovakvih konstrukcija imamo drveni kolovoz koji je izložen stalnom habajućem dejstvu pneumatika teških vozila i uticaju atmosferilija. Veze između glavnih nosača i kolovozne konstrukcije su takođe podložne oštećenju. Sve ovo dovodi do brzog propadanja kolovozne konstrukcije i potrebe za njenim stalnim održavanjem odnosno zamjenom. Neodržavana drvena kolovozna konstrukcija predstavlja slabu zaštitu čeličnim nosačima, što dovodi do njihovog propadanja i smanjenja nosivosti.

Potreba za podizanjem kvaliteta mostovskih objekata na šumskim putevima, uz istovremenu racionalizaciju troškova njihove gradnje i eksploatacije, nameće izbor tipa rasponske konstrukcije kao jedno od važnih pitanja. Ovo pitanje je važno kako pri gradnji novog mosta tako isto i pri rekonstrukciji već postojećeg objekta.

Izabrano rješenje treba da, sa jedne strane, zadovolji potrebu za što nižim troškovima gradnje i održavanja a, sa druge, da svojom kvalitetom i trajnošću, zajedno sa putnim komunikacijama na kojima se nalaze, odgovara potrebama suvremenog šumskog privređivanja i privrednog razvoja područja u kojem se nalazi.

\section{Tipovi rasponskih konstrukcija}

Danas se u savremenoj mostogradnji koriste različiti tipovi rasponskih konstrukcija. U ovom radu bit će obrađeni samo oni tipovi rasponskih konstrukcija čija je upotreba u oblasti šumarstva realna.

Primjena klasičnih drvenih rasponskih konstrukcija $u$ današnje vrijeme svedena je na minimum. Razlog leži u činjenici da preko mostova prelaze sve teža transportna sredstva, što zahtijeva velike dimenzije glavnih nosača čak i pri malim dimenzijamasvijetlog otvora mosta. Ukoliko se želi u većoj mjeri koristiti drvo kao materijal u gradnji mostova, bilo bi neophodno primjenjivati druge tipove konstrukcija (proste grede sa sedlima, proste ili dvostruke razupore), čime bi se smanjile dimenzije otvora, ali i povećao zahtjev za većom slobodnom visinom mosta.

Širu primjenu imaju lamelirane drvene konstrukcije koje, za razliku od klasičnih nemaju velike dimenzije glavnog nosača i kod većih raspona. U našoj zemlji primjena ovakvih rasponskih konstrukcija još uvijek ne postoji iako bi ona bila u potpunosti opravdana s obzirom na njihove karakteristike. Razlog zbog kojeg se ovakve rasponske konstrukcije u našoj zemlji ne koriste je trenutno visoka nabavna cijena lameliranih nosača.

Sprezanje u širem smislu predstavlja konstruktivno objedinjavanje dva materijala različitih osobina u jedinstven spregnuti nosač. U užem smislu, sprezanje je konstruktivno objedinjavanje armirano betonske ploče i čeličnog nosača (PRžULJ, M. 1989).

Pored armiranog betona i čelika, sprezati se mogu i betoni različitog kvaliteta i starosti, drveni nosači i armirano betonska ploča, drveni nosači i čelične lamele, čelik i poliuretan i drugo (PRŽULJ,M. 1989).

Kod armiranog betona iskorištena je njegova dobra čvrstoća na djelovanje sile pritiska dok malu otpornost betona na zatezanje nadomješta dejstvo čelične armature $u$ zategnutim zonama presjeka. Dominirajući materijal $\mathrm{u}$ armirano betonskim 
konstrukcijama je beton. U spregnutim konstrukcijama iskorištava se čvrstoća betona na pritisak uz istovremeno korištenje otpornosti čelika na zatezanje, djelomično na pritisak i na smičuće sile koje se javljaju na mjestima spojeva armirano betonske ploče i čeličnog nosača. Dominantni materijal u spregnutom nosaču je čelik (HORVATIĆ, D. 2003).

Male raspone $(4,0-6,0 \mathrm{~m})$ koji su i najzastupljeniji na šumskim kamionskim putevima (preko 70\%), najlakše je premostiti gradnjom armirano betonske pločaste konstrukcije. Također, sa aspekta regulacije bujičnog toka ovakav tip konstrukcije čini monolitnu konstrukciju, pri čemu je njena stabilnost u uslovima optimalnog izbora svijetlog otvora kao i visine konstrukcije u potpunosti zadovoljavajuća. No, sa porastom raspona debljina armirano betonske ploče naglo raste te ona postaje nepodesna zbog velike težine i potrebe za gradnjom obimne skele i oplate. Ako se gradi armirano betonski most, kod većih raspona potrebno je pribjegavati drugim rješenjima - gradnji armirano betonske konstrukcije kao rebraste ili primjeni prednaprezanja betona. U ovakvim slučajevima, za mostove malih i srednjih raspona, može biti interesantna primjena prefabriciranih elemenata od prednapregnutog betona. Prednapregnuti prefabricirani nosači mogu naći svoju primjenu i u gradnji mostova na šumskim putevima zbog kvalitete takvih konstrukcija i brze gradnje. Ipak, visoka cijena proizvodnje nosača (visoke marke betona, kablovi za prednaprezanje od visokovrijednog čelika) te visoka cijena transporta i montaže, čine ih često neekonomičnim kada se uzmu u obzir ekonomski uvjeti gradnje komunikacija u šumarstvu.

U poređenju sa armirano betonskim konstrukcijama, spregnuti mostovi čelik-beton imaju znatno manje povećanje težine rasponske konstrukcije sa povećanjem raspona mosta. Upotrebom spregnutih konstrukcija mogu se lako, jednim rasponom uz neznatno povećanje vlastite težine, na šumskim putevima, premostiti rasponi od 10, 15 i više metara.

Mogućnost upotrebe spregnutih konstrukcija za male mostove na šumskim putevima interesantna je, osim za gradnju novih, i kod pitanja rekonstrukcije starih drvenih i čeličnih mostova. Ovakvi mostovi imaju lake rasponske konstrukcije. Njihova zamjena teškim armirano betonskim konstrukcijama, često je povezana sa složenijim i skupljim zahvatima na donjem stroju mosta. Znatno lakše, kvalitetne i cijenom kompetitivne spregnute konstrukcije nameću se u ovakvim slučajevima kao povoljna rješenja. Mala težina omogućuje, ovisno od slučaja, zadržavanje obalnih stubova uz manje rekonstrukcije. Betonska kolovozna ploča kod ovakvih konstrukcija je znatno manjih dimenzija i za njeno betoniranje je potrebna manja skela i oplata $u$ poređenju sa armirano betonskom pločom. U ovakvim slučajevima čelični nosači služe kao potpora za oplatu i nije potrebna gradnja stubova.

Kao sredstva sprezanja, odnosno prenosa smičuće sile sa armirano betonske ploče na čelične nosače, najčešće se primjenjuju različiti oblici moždanika.

Za spregnute konstrukcije primjenjuju se marke betona MB30 - MB60. Povoljne marke betona za upotrebu čepova sa glavom su od MB30 do MB50. MB30.

Za mostove malih raspona na šumskim putevima može se preporučiti marka betona

Minimalna debljina armirano betonske ploče za putne mostove je $16 \mathrm{~cm}$ (PRŽULJ,M.1989). 
Za spregnute mostove malih raspona na šumskim putevima podesna je upotreba valjanih I profila standardnih dimenzija poprečnog presjeka. Po potrebi se nosivost čelličnih nosača može povećati zavarivanjem dodatne lamele na donjem pojasu.

Najpodesniji broj čeličnih nosača za male širine mostova je 3 - 4 nosača u poprečnom presjeku.

\section{Metod rada - Work Method}

\section{Uporedna analiza rasponskih konstrukcija od različitih materijala}

Uporedna analiza rasponskih konstrukcija izvršena je na osnovu tehničkih pokazatelja. Poređene su rasponske konstrukcije od različitih materijala i to prostih sistema koji se najčešće javljaju na šumskim putevima. Drveni mostovi su sistema proste grede sa sedlom i proste grede sa sedlom i kosnikom. Čelični mostovi su tipa proste grede sa valjanim profilima INP i drvenim kolovozom. Armirano betonski most je tipa armirano betonska ploča sa armaturom u zategnutoj zoni. Spregnuti mostovi su tipa proste grede sa punostjenim valjanim INP profilima i armirano betonskom kolovoznom pločom debljine $16 \mathrm{~cm}$. Sredstva sprezanja kod ovih mostova su elastični moždanici tipa čepa sa glavom, i to jedan moždanik u poprečnom presjeku zavaren na sredini gornje lamele čeličnog nosača. Predviđeno je radioničko zavarivanje moždanika na čelične nosače prema projektu i transport pripremljenih nosača na mjesto gradnje. U analizu su uzeta dva tipa poprečnog presjeka konstrukcije - sa tri i četiri čelična nosača u poprečnom presjeku.

Uporedna analiza, zasniva se na detaljnim proračunima nosive konstrukcije.

$\mathrm{Na}$ osnovu ranijih istraživanja (EŠKERICA,V. 1974) i provedenih terenskih pregleda (KovAČEVIĆ, B. 2005), može se zaključiti da se veličine raspona odnosno svijetlih otvora mostova na šumskim putevima u velikom procentu (preko 90\%) kreću u granicama od 4 do $10 \mathrm{~m}$.

Ovo je bila polazna osnova kod određivanja svijetlih otvora mostova za uporednu analizu. Donja veličina svijetlog otvora od $4 \mathrm{~m}$ predstavlja granicu između mostova i propusta, dok su mostovi svijetlog otvora preko $10 \mathrm{~m}$ veoma rijetki na šumskim putevima u Bosni i Hercegovini. Analizirani su svijetli otvori od 4, 6, 8 i 10 $\mathrm{m}$. Poređenje konstrukcija je izvršeno na svim svijetlim otvorima, osim drvenog mosta sistema prosta greda sa sedlom i kosnikom koji nije analiziran za svijetli otvor od $4 \mathrm{~m}$.

Tehnički elementi rasponskih konstrukcija, značajni za njihovo poređenje, a prezentirani u ovom radu su: ukupna visina nosive konstrukcije i vlastita težina konstrukcije. Takođe je razmatrano i učešće momenta od vlastite težine konstrukcije $\mathrm{i}$ od korisnog (pokretnog) opterećenja u ukupnom momentu savijanja.

Pored tipa rasponske konstrukcije u analizu je uključeno i stanje mosnih glava, kao i postojanje mosnih krila (dužina krila) koji predstavljaju jedan od ključnih faktora $\mathrm{u}$ regulaciji kretanja vodne mase pri prolasku kroz otvor mosta. 


\section{Rezultati istraživanja - Results of the Research}

\section{Tehnički elementi konstrukcija}

Tabela 1. Pregled vlastite težine rasponske konstrukcije mostova

Table no. 1 Summary of bridge super-structure weights

\begin{tabular}{|c|c|c|c|c|}
\hline \multirow{3}{*}{$\begin{array}{l}\text { Vrsta rasponske konstrukcije } \\
\text { Construction type }\end{array}$} & \multicolumn{4}{|c|}{$\begin{array}{l}\text { Veličina otvora mosta } \\
\text { Bridge clear length }\end{array}$} \\
\hline & 4,00 & 6,00 & 8,00 & 10,00 \\
\hline & \multicolumn{4}{|c|}{$\begin{array}{l}\text { Težina konstrukcije u KN/m² } \\
\text { Super-structure weight in } \mathrm{KN} / \mathrm{m}^{2}\end{array}$} \\
\hline $\begin{array}{l}\text { Drveni most-sistem prosta greda sa sedlima } \\
\text { Timber bridge-simple beam system with saddles }\end{array}$ & 2,56 & 2,84 & 2,56 & 2,65 \\
\hline $\begin{array}{l}\text { Drveni most-sistem prosta greda sa sedlima i kosnicima } \\
\text { Timber bridge-simple beam system with saddles and struts }\end{array}$ & - & 3,06 & 2,79 & 2,94 \\
\hline $\begin{array}{l}\text { Čelični most sa drvenim kolovozom-sistem prosta greda sa INP nosačima } \\
\text { Steel bridge with sawn lumber plank deck-simple beam system with } \\
\text { steel I beams }\end{array}$ & 2,66 & 3,15 & 3,27 & 3,51 \\
\hline $\begin{array}{l}\text { Armirano betonska pločasta konstrukcija } \\
\text { Reinforced concrete slab }\end{array}$ & 11,15 & 13,65 & 16,15 & 19,15 \\
\hline $\begin{array}{l}\text { Spregnuta konstrukcija tipa prosta greda sa tri čelična nosača INP } \\
\text { Composite structure-simple beam system with three steel I beams }\end{array}$ & 8,18 & 8,83 & 9,04 & 9,58 \\
\hline $\begin{array}{l}\text { Spregnuta konstrukcija tipa prosta greda sa četiri čelična nosača INP } \\
\text { Composite structure-simple beam system with four steel I beams }\end{array}$ & 8,17 & 8,92 & 9,28 & 9,59 \\
\hline
\end{tabular}

Tabela 2. Pregled visine nosive konstrukcije mostova

Table no. 2. Summary of bridge super-structure heights

\begin{tabular}{|l|c|c|c|c|}
\hline \multicolumn{1}{|c|}{$\begin{array}{l}\text { Vrsta rasponske konstrukcije } \\
\text { Construction type }\end{array}$} & \multicolumn{4}{|c|}{$\begin{array}{c}\text { Veličina otvora mosta } \\
\text { Bridge clear length }\end{array}$} \\
\cline { 2 - 5 } & 4,00 & 6,00 & \multicolumn{1}{|c|}{8,00} & 10,00 \\
\cline { 2 - 5 } & \multicolumn{2}{|c|}{$\begin{array}{c}\text { Ukupna visina konstrukcije u cm } \\
\text { Total super-structure height in cm }\end{array}$} \\
\hline $\begin{array}{l}\text { Drveni most-sistem prosta greda sa sedlima } \\
\text { Timber bridge-simple beam system with saddles }\end{array}$ & 79 & 87 & 79 & 82 \\
\hline $\begin{array}{l}\text { Drveni most-sistem prosta greda sa sedlima i kosnicima } \\
\text { Timber bridge-simple beam system with saddles and struts }\end{array}$ & - & 82 & 75 & 79 \\
\hline $\begin{array}{l}\text { Celični most sa drvenim kolovozom-sistem prosta greda sa INP } \\
\text { nosačima } \\
\text { Steel bridge with sawn lumber plank deck-simple beam system with } \\
\text { steel I beams }\end{array}$ & 53 & 61 & 65,5 & 70,5 \\
\hline $\begin{array}{l}\text { Armirano betonska pločasta konstrukcija } \\
\text { Reinforced concrete slab }\end{array}$ & 47 & 57 & 67 & 79 \\
\hline $\begin{array}{l}\text { Spregnuta konstrukcija tipa prosta greda sa tri čelična nosača INP } \\
\text { Composite structure-simple beam system with three steel I beams }\end{array}$ & 63 & 73 & 80 & 90 \\
\hline $\begin{array}{l}\text { Spregnuta konstrukcija tipa prosta greda sa četiri čelična nosača INP } \\
\text { Composite structure-simple beam system with four steel I beams }\end{array}$ & 61 & 71 & 77,5 & 85 \\
\hline
\end{tabular}


Tabela 3. Pregled procentualnog učešća momenta stalnog i pokretnog opterećenja u ukupnom momentu savijanja

Table no. 3 Summary of proportional participation of dead and live load in total bending moment

\begin{tabular}{|c|c|c|c|c|c|c|c|c|}
\hline \multirow{4}{*}{$\begin{array}{l}\text { Vrsta rasponske konstrukcije } \\
\text { Construction type }\end{array}$} & \multicolumn{8}{|c|}{ Veličina otvora mosta - Bridge clear length } \\
\hline & \multicolumn{2}{|c|}{4,00} & \multicolumn{2}{|c|}{6,00} & \multicolumn{2}{|c|}{8,00} & \multicolumn{2}{|c|}{10,00} \\
\hline & \multicolumn{8}{|c|}{$\%$} \\
\hline & $\mathrm{Mg}$ & $\mathrm{Mp}$ & $\mathrm{Mg}$ & $\mathrm{Mp}$ & $\mathrm{Mg}$ & $\mathrm{Mp}$ & $\mathrm{Mg}$ & $\mathrm{Mp}$ \\
\hline $\begin{array}{l}\text { Drveni most-sistem prosta greda sa sedlima } \\
\text { Timber bridge-simple beam system with saddles }\end{array}$ & 2,8 & 97,2 & 3,9 & 96,1 & 2,8 & 97,2 & 3,4 & 96,6 \\
\hline $\begin{array}{l}\text { Drveni most-sistem prosta greda sa sedlima i kosnicima } \\
\text { Timber bridge-simple beam system with saddles and struts }\end{array}$ & - & - & 3,2 & 96,8 & 2,3 & 97,7 & 2,6 & 97,4 \\
\hline $\begin{array}{l}\text { Čelični most sa drvenim kolovozom-sistem prosta greda } \\
\text { sa INP nosačima } \\
\text { Steel bridge with sawn lumber plank deck-simple beam } \\
\text { system with steel I beams }\end{array}$ & 6,2 & 93,8 & 8,9 & 91,1 & 11,8 & 88,2 & 13,4 & 86,6 \\
\hline $\begin{array}{l}\text { Armirano betonska pločasta konstrukcija } \\
\text { Reinforced concrete slab }\end{array}$ & 30,3 & 69,7 & 41,5 & 58,5 & 53,7 & 46,3 & 60,6 & 39,4 \\
\hline $\begin{array}{l}\text { Spregnuta konstrukcija tipa prosta greda sa tri čelična } \\
\text { nosača INP } \\
\text { Composite structure-simple beam system with three steel } \\
\text { I beams }\end{array}$ & 17,5 & 82,5 & 30,4 & 69,6 & 39,7 & 60,3 & 47,0 & 53,0 \\
\hline $\begin{array}{l}\text { Spregnuta konstrukcija tipa prosta greda sa četiri čelična } \\
\text { nosača INP } \\
\text { Composite structure-simple beam system with four steel I } \\
\text { beams }\end{array}$ & 16,9 & 83,1 & 29,2 & 70,8 & 40,3 & 59,7 & 48,3 & 51,7 \\
\hline
\end{tabular}

Mg - Moment od stalnog opterećenja; Mp - Moment od pokretnog opterećenja

$\mathrm{Mg}$ - Dead load bending moment; Mp - Live load bending moment

\section{Diskusija - Discussion}

\section{Tehničke osobine konstrukcija:}

Armirano betonska ploča na svim razmatranim otvorima ima najveću težinu. Spregnute konstrukcije se po težini nalaze između lakih drvenih i čeličnih konstrukcija, sa jedne strane, i teške armirano betonske pločaste konstrukcije, sa druge strane. Porast težine spregnutih konstrukcija je mali i u tom smislu se spregnute konstrukcije ponašaju slično drvenim i čeličnim. To je posljedica konstantne visine armirano betonske ploče $i$ manje težine čeličnih nosača. Kod većih raspona mostova, ako se ovi grade kao armirano betonske konstrukcije, mora se pribjegavati drugim rješenjima: gradnji mostova sa dva ili više otvora kontinuiranih sistema; olakšavanju armirano betonskih ploča upotrebom cijevi od kartona, lesonita ili čeličnog lima za uzdužne šupljine; gradnji rebrastih ili grednih konstrukcija ili upotrebi prednaprezanja armiranog betona. Primjena ovakvih metoda na šumskim putevima usložnjava i poskupljuje gradnju.

U pogledu visine rasponske konstrukcije armirano betonska ploča ima najveći porast. Međutim, do otvora $6,0 \mathrm{~m}$, koji su i najčešći u šumarstvu, visina ovih 
konstrukcija je najmanja $(61 \mathrm{~cm})$. Ova karakteristika je pozitivna kada je u pitanju proticaj bujičnih voda koje zahtijevaju što veće slobodne visine mosta, te uz relativno veliku težinu $\mathrm{AB}$ mostova i njihovu kompaktnost ovakvim konstrukcijama u odnosu na druge daje prednost.

$\mathrm{Na}$ većim otvorima najmanju visinu konstrukcije ima čelična konstrukcija sa drvenim kolovozom, a na malim otvorima od 4 do $6 \mathrm{~m}$ armirano betonska ploča. Kod drvenih konstrukcija sa seldom i seldom i kosnikom porast konstruktivne visine ovisan je o broju riječnih stubova odnosno veličini raspona. Po visini rasponske konstrukcije drveni mostovi navedenih sistema na većim otvorima stoje na sredini između čeličnih i spregnutih konstrukcija, a na malim otvorima drveni mostovi imaju najveće visine konstrukcije.

Visina konstrukcije mosta važna je u slučajevima kada se zbog karakteristika korita vodotoka koji se premoštava ili zbog karakteristika putne komunikacije, te nastojanja da se prepreka premosti sa najmanjim mogućim rasponom, želi postići što manja ukupna visina ili se za istu ukupnu visinu želi obezbijediti što veći proticajni profil.

$\mathrm{Na}$ visinu nosive konstrukcije se može uticati različitim konstruktivnim mjerama te izborom boljih materijala za gradnju. U tom pogledu spregnute konstrukcije su u prednosti jer se nosivi presjek sastoji od dva materijala- čelika i armiranog betona, pa su time mogućnosti djelovanja, s obzirom na različite osobine dva materijala veće. Odnos učešća momenta od vlastite težine i od pokretnog opterećenja u ukupnom momentu savijanja povoljniji je kod lakih konstrukcija (drvene i čelične).

Armirano betonska ploča već na otvoru od $8 \mathrm{~m}$ ima veće učešće vlastite težine u ukuponom opterećenju konstrukcije u odnosu na korisno opterećenje. Spregnute konstrukcije stoje između lakih drvenih i čeličnih, sa jedne strane, i teških armirano betonskih konstrukcija, sa druge strane.

Kad je u pitanju odnos tipa rasponske konstrukcije i bujičnih tokova, može se reći da male raspone 4,0 - 6,0 m povoljna rješenja predstavljaju $A B$ ploče, jer one do raspona 6,0 m imaju najpovoljniju ukupnu visinu konstrukcije, a uz zadovoljavajuću otpornost na vanjske atmosferilije (posebno kad je u pitanju uticaj bujičnih voda). Kod raspona 6,0 - 10,0 m AB konstrukcije imaju nepovoljnu ukupnu konstruktivnu visinu, dok je kod ovih raspona za spregnute konstrukcije (AB - čelik) konstruktivna visina najpovoljnija, uz zadovoljavajuću otpornost na uticaj atmosferilija, pa se ove konsrukcije nameću kao optimalno rješenje po pitanju bujičnih voda.

\section{Zaključak - Conclusion}

Na osnovu sprovedene analize može se reći da su armirano betonske pločaste konstrukcije kod malih raspona $(4-6 \mathrm{~m})$ kvalitetno rješenje čije konstruktivne karakteristike u potpunosti zadovoljavaju uslove savremenog saobraćaja u šumarstvu. Nadalje, kod istih se kao i kod gradnje mosnih glava i mosnih krila koristi identičan materijal (kombinacija betona $\mathrm{i}$ armiranog betona), što cijeloj konstrukciji daje monolitan izgled, povećava stabilnost i bezbjednost od negativnog uticaja bujičnog toka. 
Spregnute konstrukcije čelik-beton su također veoma kvalitetna rješenja u gradnji mostova malih raspona na šumskim putevima. Posebno na onim šumskim putevima gdje je veći intenzitet saobraćaja i gdje postoji potreba za boljim kvalitetom saobraćajnice i objekata na njoj. Kao što je i naprijed spomenuto, šumski putevi su sredstva trajnog otvaranja šumskih područja i nerijetko imaju značaja, ne samo za razvoj šumarske privrede nego i turizma te drugih aktivnosti lokalnog stanovništva.

Radi se o veoma kvalitetnim konstrukcijama koje po svojoj trajnosti ne zaostaju za armirano betonskim. Njihov poseban značaj jeste u tome što mogu biti povoljna rješenja za kvalitetnu i trajnu rekonstrukciju dotrajalih drvenih i čeličnih mostova sa drvenim kolovozom. U ovakvim slučajevima armirano betonske pločaste konstrukcije su, prvenstveno zbog velike težine i postupka izvođenja na nedostupnim mjestima, često puta nepodesno rješenje.

Kao što je iz prezentiranih podataka vidljivo, spregnuti mostovi čelik-beton i tehnički i ekonomski predstavljaju konkurenciju armirano betonskim pločastim konstrukcijama. Sa druge strane se posebno drveni, ali i čelični mostovi sa drvenim kolovozom, mogu, na način kako su se ranije radili a i sada, smatrati isključivo privremenim, a nikako trajnim rješenjima. Stoga se primjena tehnologije sprezanja čeličnih nosača i armirano betonske ploče nameće kao jedno od najpovoljnijih rješenja za njihovu sanaciju i trajno rješavanje.

Provedena analiza ukazuje da se prilikom gradnje novih mostovskih konstrukcija te rekonstrukcije postojećih nije dovoljno posvetila pažnja veličini krila mosta kod svih tipova rasponskih konstrukcija, što je u većini slučajeva imalo negative posljedice kad je u pitanju podkopavanje mosnih glava prilikom bujičnih pojava i urušavanja istih.

\section{Literatura - References}

1. EŠKERICA, V.: Uporedna analiza primjenjivosti drvenih, čeličnih i armirano betonskih mostova prostih sistema na šumskim putevima. Magistarski rad. Sarajevo, 1974.

2. HoRVATIĆ, D.: Spregnute konstrukcije čelik-beton, Masmedia Zagreb, 2003.

3. JAHIĆ, M.: Uređivanje bujica, Šumarski fakultet Sarajevo, 2006. godina

4. KOVAČEVIĆ, B.: Racionalizacija gradnje mostova na šumskim putevima primjenom suvremenih rasponskih konstrukcija. Magistarski rad. Šumarski fakultet. Sarajevo, 2005.

5. PRŽULJ, M.: Spregnute konstrukcije: Teoretske osnove, proračun i konstruisanje sprezanja čelika i betona kod nosača, ploča i stubova sa primjenom u mostogradnji i visokogradnji , IRO “Građevinska knjiga” Beograd, 1989. 


\section{Sažetak - Summary}

Bridges represent the most significant objects on forest roads, both based on the costs of their construction and their technical characteristics. The construction of new and reconstruction of the existing bridges for forest trucks is solicited as a continued task ahead of forest professionals.

The paper is intended to point at the significance of the choice of the type of bridge construction during the reconstruction of the existing or construction of the new bridges, as well as the influence of the choice of the type of construction to flood flows which are in most cases bridged over by such construction structures.

The performed investigation indicated that during the construction of the bridges, various kinds of materials can be used with technical characteristics that mutually differ. Leastways, it has a direct influence to the type of the bridge construction material. The study also indicated that previous reconstructions were done in such a manner that they did not solve the problem of bridging over in the long run. The reconstructions were mainly done with raw conifer material which was not impregnated, reducing the durability of such structures to a period spaning from 5 to 10 years.

In the usual practice, for over bridging water flows, we often apply solutions in the form of tubes of different profiles that are placed in one or more rows. Such solutions are not convenient as the tubes get stuck with first flood flow currents. By a thorough analysis of durability of different types of bridge constructions, technical solutions, as well as safety of the bridges during the passage of flood flow it can be reported that rather reliable solutions for spans of 4,0-6,0 are $\mathrm{AB}$ bridges, while for the spans ranging between 6,0 and 10,0 m we would opt for composite constructions (steel concrete) as best quality solution. Naturally, other types of bridge constructions should not be neglected in reconstruction and construction of bridges, however, each separate case requires separate analysis and the results of such analyses will determine the most appropriate type of spanning construction whether it is the question of technical/technological or economical construction component. 